\title{
Feasibility of early intensive blood pressure lowering in intracerebral hemorrhage - use of a simple systematic treatment algorithm
}

S. Homburg' ${ }^{1}$ R. Ankerlund Blauenfeldt ${ }^{1}$, S. Kilian ${ }^{1}$, T. Terkelsen ${ }^{2}$, D. Damgaard ${ }^{1}$, S. Paaske Johnsen

G. Andersen', N. Hjort'1

${ }^{1}$ Aarhus University Hospital, Department of Neurology, ${ }^{2}$ Aarhus University Hospital, Department of Clinical Genetics, ${ }^{3}$ Aalborg University, Department of Clinical Medicine, ${ }^{4}$ Aalborg University Hospital, Department of Clinical Medicine, Denmark

\section{Introduction}

More than $75 \%$ have elevated blood pressure (BP) in the acute phase of intracerebral hemorrhage $(\mathrm{ICH})$.

$\mathrm{ICH}$ treatment at Aarhus University Hospital: Keep systolic BP $<140 \mathrm{~mm} \mathrm{Hg}$.

$\rightarrow$ It is associated with decreased hematoma expansion and a borderline reduction of disability or death after 3 months ${ }^{1}$.

\section{Aim}

To investigate whether a rapid $\mathrm{BP}$ reduction can be obtained in everyday clinical practice using a simple treatment algorithm.

\section{Method}

The algorithm:

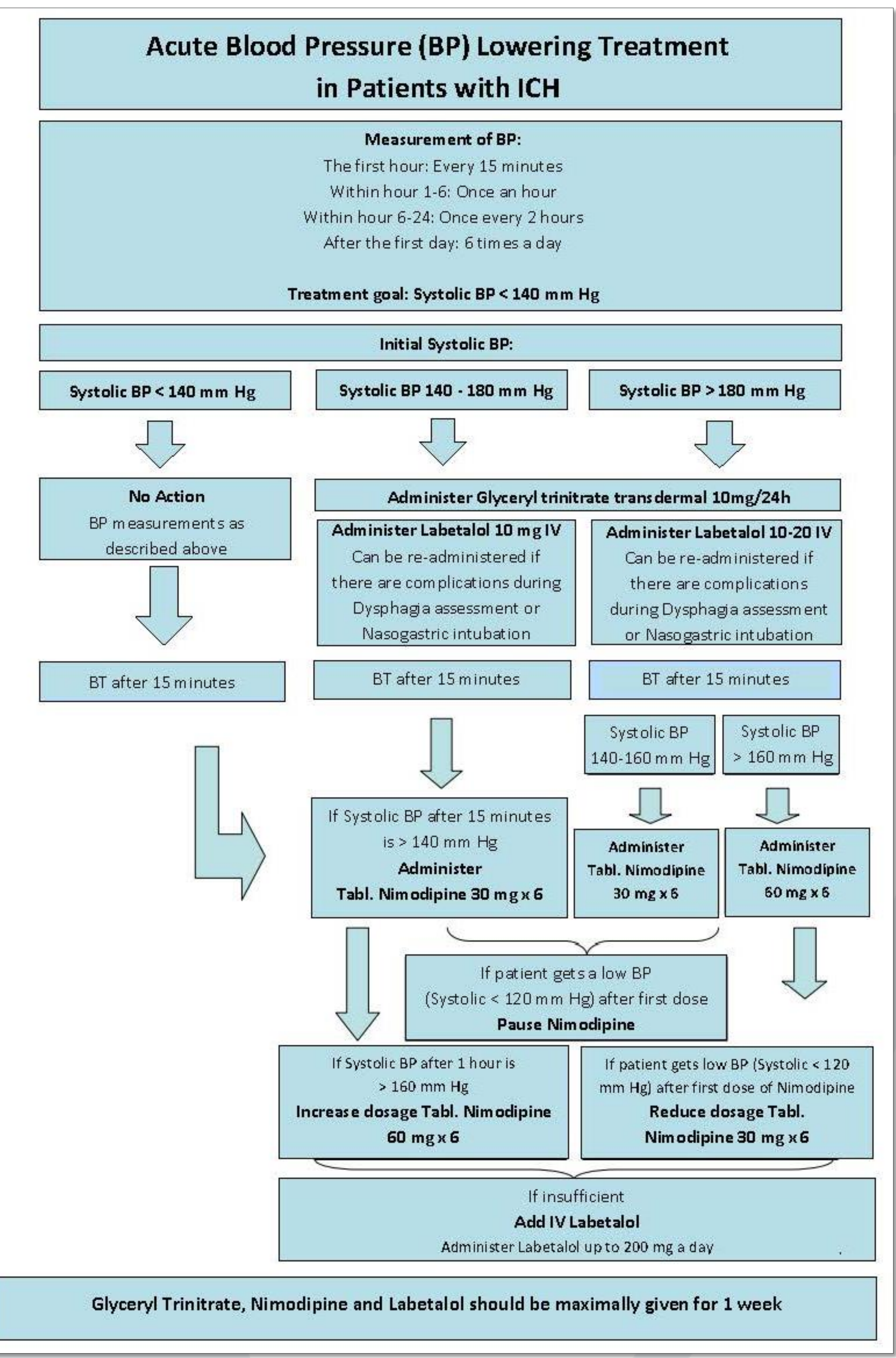

Prospective single-center cohort study during one year.

157 acute patients with spontaneous $\mathrm{ICH}$ were included.

134 patients with systolic BP > $140 \mathrm{~mm} \mathrm{Hg}$ were treated.

\section{Contact:}

Pre-graduate scholar

Sif Homburg

E-mail: sifhom@rm.dk

Conflicts of interrest: None

\section{Results}
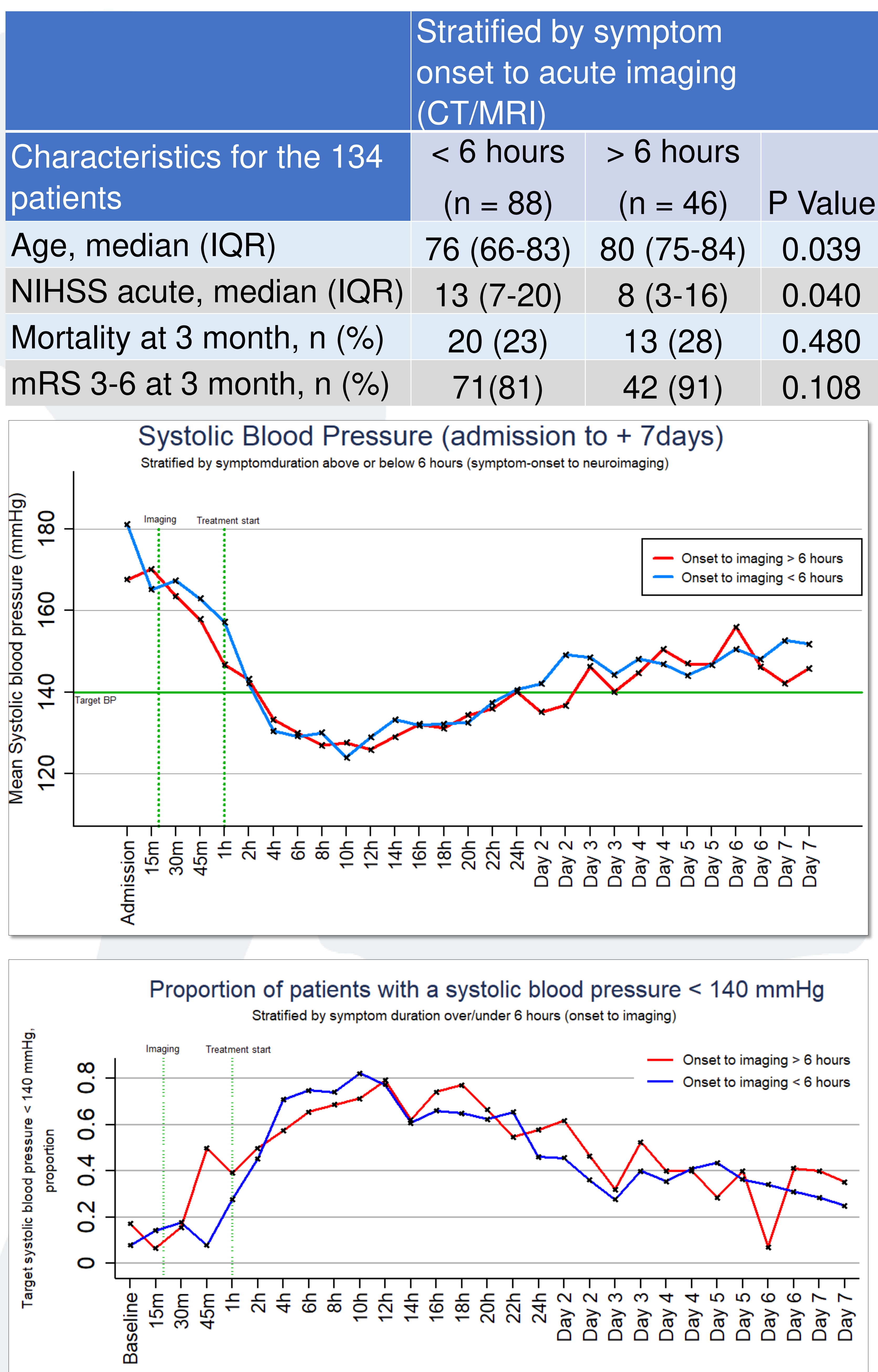

Within 1 hour, from admission, $29 \%$ of patients with a symptom duration $<6$ hours reached target systolic BP and $76 \%$ within 6 hours.

For the patients with a symptom duration $>6$ hours $41 \%$ and $68 \%$ reached target BP after 1 and 6 hours, respectively.

Acute antihypertensive drugs used: 93\% were treated with glyceryl trinitrate, $95 \%$ with labetalol and $60 \%$ with nimodipine.

Only $2 \%$ were treated with other drugs not mentioned in the algorithm.

\section{Conclusion}

Rapid BP reduction can be obtained in everyday clinical practice using a simple treatment algorithm. 